\title{
Neoglycosylated Collagen: Effect on Neuroblastoma F-11 Cell Lines
}

\author{
Antonella Sgambato ${ }^{1,+}$, Valentina Pastori ${ }^{1,+}{ }^{,}$Laura Russo ${ }^{1}$, , Simone Vesentini ${ }^{2}$, \\ Marzia Lecchi ${ }^{1, *(\mathbb{D})}$ and Laura Cipolla ${ }^{1, *(\mathbb{D}}$ \\ 1 Department of Biotechnology and Biosciences, University of Milano-Bicocca, Piazza della Scienza 2, \\ 20126 Milano, Italy; antonella.sgambato@unimib.it (A.S.); valentina.pastori@unimib.it (V.P.); \\ laura.russo@unimib.it (L.R.) \\ 2 Department of Electronics, Information and Bioengineering, Politecnico di Milano, via Camillo Golgi 39, \\ 20133 Milano, Italy; simone.vesentini@polimi.it \\ * Correspondence: marzia.lecchi1@unimib.it (M.L.); laura.cipolla@unimib.it (L.C.) \\ $\dagger$ These authors contributed equally to the work.
}

Academic Editor: Tomasz Plech

Received: 10 September 2020; Accepted: 21 September 2020; Published: 23 September 2020

\begin{abstract}
The regeneration of the nervous system is a challenging task. Currently, regenerative medicine approaches that exploit nature-inspired cues are being studied and hold great promise. The possibility to use protein-based matrices functionalized with small oligo- and monosaccharides is of interest since these can be finely tuned to better mimic the native environment. Collagen has been selected as a promising material that has the potential to be further tailored to incorporate carbohydrates in order to drive cell behavior towards neuroregeneration. Indeed, the grafting of carbohydrates to collagen 2D matrices is proved to enhance its biological significance. In the present study, collagen 2D matrices were grafted with different carbohydrate epitopes, and their potential to drive F-11 neuroblastoma cells towards neuronal differentiation was evaluated. Collagen functionalized with $\alpha$-glucosides was able to differentiate neuroblastoma cells into functional neurons, while sialyl $\alpha-(2 \rightarrow 6)$-galactosides stimulated cell proliferation.
\end{abstract}

Keywords: collagen; biomaterials; carbohydrates; chondroitin sulfate; F-11 cell line; sialic acid; glucose; galactose

\section{Introduction}

Nervous system repair and/or function restoration after injury, traumas or neurological disorders, such as neurodegenerative diseases, is still a challenging and unsolved problem. The main approaches currently being proposed include pharmacological treatments (limited by drug delivery issues [1]) that result in the slowing of disease progression [2] and regenerative medicine approaches [3,4], all of which are flanked by the improvement of our knowledge of the nervous system.

Regenerative medicine approaches often rely on the combination of biomaterials able to support tissue regeneration, cells (autologous, xeno- or autografts) and signaling cues able to drive cell responses towards tissue regeneration. Collagen, the most abundant protein in the human body [5], is emerging as a suitable biomaterial for regenerative medicine [6], including for nervous system repair [7-9], due to its biocompatibility, its biodegradability and its mechanical properties matching the nervous tissue, in the form of hydrogels [10]. In addition, interest in the role of collagen in the nervous system has been increasing over recent decades, given the role of collagen in signal transduction and nerve regeneration [11,12].

Besides collagen, carbohydrates play a significant role as key signaling biochemical cues and can be considered useful molecules in regenerative medicine approaches [13], including nervous 
tissue regeneration [14]. The ability of carbohydrates to drive neuronal cell behavior has been shown in previous works $[15,16]$. Moreover, collagen itself is constitutively glycosylated at hydroxylysine residues with the disaccharide $\alpha-(1 \rightarrow 2)$-glucosylgalactoside 1 (Figure 1) [17]. Thus, new synthetic glycosylated collagen matrices grafted with relevant saccharides involved in nervous system regulation and development have been prepared and evaluated.

A.

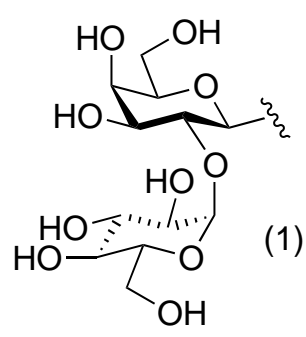<smiles>OCC1(O)C(O)C(O)C2CCCC(O)C1O2</smiles>

(2)

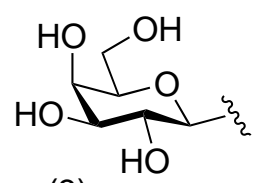
Collagen matrix
$\left(1 \mathrm{mg} / \mathrm{cm}^{2}\right)$

(3)

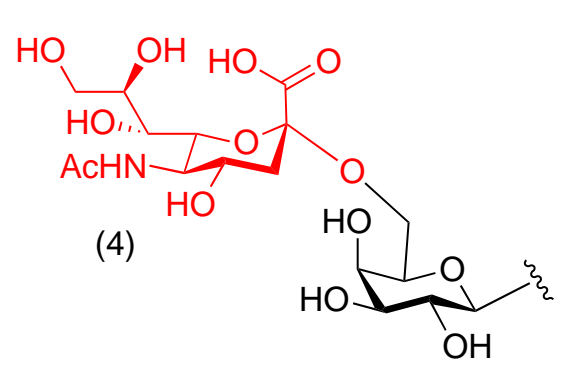

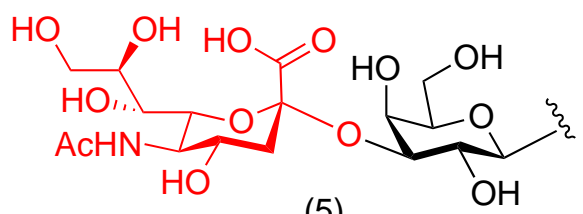

(5)

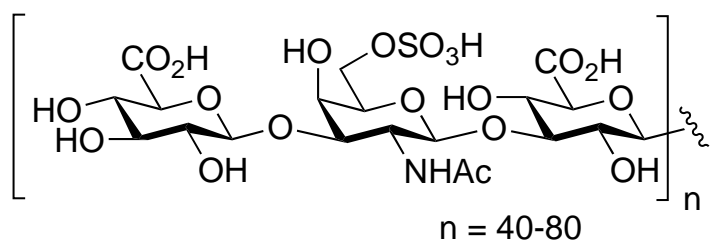

B.

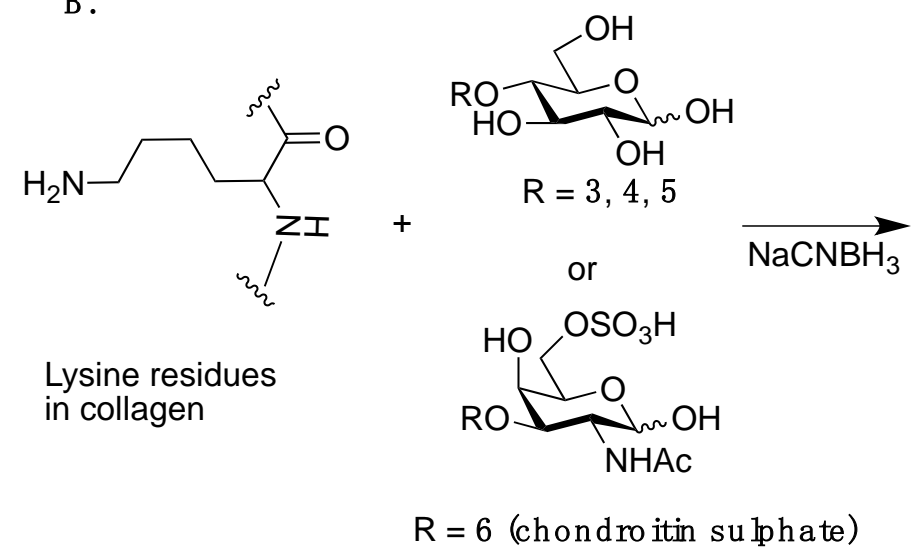<smiles>[Z]C(=O)C(CCCCNCC(O)C(O)CO)C(C)C(=O)O</smiles>

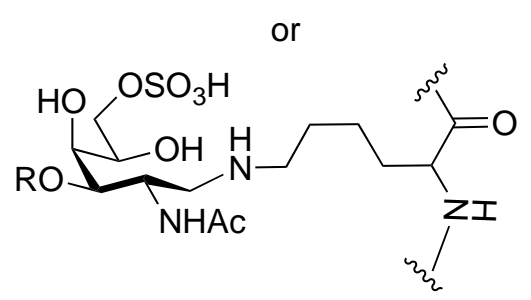

Figure 1. (A) Carbohydrate epitopes grafted to collagen matrices: (1) the native collagen glycosylation motif, (2) $\alpha$-glucosides, (3) $\beta$-galactosides, (4) sialyl $\alpha$-(2 $\rightarrow 6$ )-galactoside, (5) sialyl $\alpha$-(2 $\rightarrow 3)$-galactoside, (6) chondroitin sulphate. (B) Grafting chemistry for collagen matrix functionalization.

\section{Results and Discussion}

We previously showed that carbohydrate epitopes grafted to collagen are able to stimulate specific cell responses, depending on the combination of epitope and cell line [16,18-20].

Since carbohydrates are deeply involved in neuronal development, we explored F-11 cell behavior in the presence of collagen matrices grafted with different carbohydrate epitopes (Figure 1A). 
Within this framework, we showed that $\alpha$-glucosides grafted to collagen 2D matrices (2, Figure 1A) are able to drive neuroblastoma F-11 cell lines to differentiate into functional neurons [16].

In this work, galactosides (3), sialyl $\alpha-(2 \rightarrow 6)$-galactoside (4), sialyl $\alpha-(2 \rightarrow 3)$-galactoside (5) and chondroitin sulphate (6) were selected for collagen 2D matrices grafting.

Galactosides are found in galactosylceramides present in myelin, and in the myelin sheath. Studies suggest that galactosides are relevant for the myelination process and/or in myelin function [21]. Galactosides were included in polymeric materials grafted with small carbohydrate epitopes, together with L-fucose, $N$-acetylglucosamine Fuc- $\alpha-(1 \rightarrow 2)$-Gal and Fuc- $\alpha-(1 \rightarrow 3)$-GlcNAc; their potential to stimulate a neuronal response toward hippocampal neurons [22] was evaluated, and few of them were able to stimulate neurite outgrowth.

Sialyl $\alpha$-(2 $\rightarrow 3)$-galactoside, sialyl $\alpha-(2 \rightarrow 6)$-galactoside and chondroitin sulphate grafted to collagen were also investigated. Sialic acids are involved in several biological functions, including neuronal development, especially in the form of gangliosides, a lipid class; they are usually found as terminal moieties linked to D-galactose residues through $\alpha-(2 \rightarrow 6)$ - or $\alpha-(2 \rightarrow 3)$-linkages $(4$ and 5 , Figure 1A). $\alpha-(2 \rightarrow 3)$-linked sialosides are the most common. The interaction of the sialic acid-binding immunoglobulin-like lectins (Siglec) [23] with sialosides exposed by gangliosides on the axon regulates the formation and maintenance of the myelin-axon organization and is involved in demyelinating disorders, such as multiple sclerosis; thus, sialosides may provide new opportunities in nervous system tissue engineering after central nervous system (CNS) injury or disease, promoting axon regeneration. To the best of our knowledge, no sialic acid grafted biomaterials have been proposed for neural tissue regeneration; however, we showed that collagen grafted with $\alpha-(2 \rightarrow 3)$-galactosides upregulate genes related to osteogenesis, while sialyl $\alpha-(2 \rightarrow 6)$-galactosides influence chondrogenesis marker expression [18].

Chondroitin sulphate (CS) is an abundant component of the brain extracellular matrix (ECM), and together with another glycosaminoglycan, hyaluronan, it forms macromolecular aggregates in the perineuronal nets, which cover cell bodies and the proximal part of neurites of several neuronal populations. CS is usually linked to proteins, affording the so-called proteoglycans. Soluble chondroitin sulphate proteoglycan (CSPG) and substratum-bound CSPG have different effects on neuronal growth cone behavior. Substratum-bound CSPG inhibits neurite outgrowth and the rate of neurite elongation of dorsal root ganglion (DRG) neurons [24]. CS is largely used in biomaterial design for bone, cartilage and neural tissue regeneration [25]. In addition, biomaterials grafted with chondroitin sulphate-derived disaccharides have been proposed, and researchers have shown that biomaterials grafted with chondroitin sulphate motifs constitute interesting approaches towards neural cell differentiation and neural tissue regeneration [26]. Moreover, we recently synthesised a chimeric proteoglycan composed of collagen and CS [27], mimicking the covalent link between the protein and the polysaccharide in proteoglycans and guaranteeing the native orientation of the glycan chain protruding from the protein backbone. Here we propose the evaluation of this chimeric proteoglycan as a biomaterial for neural tissue regeneration.

Thus, carbohydrate motifs 2-6 (Figure 1A) were grafted to collagen matrices, taking advantage of the complementary reactivity of lysine side-chain amino groups and the reducing end of suitable saccharides (Figure 1B), exposing the desired carbohydrate epitopes 2-6: the reaction in reducing conditions by $\mathrm{NaCNBH}_{3}$ regioselectivity affords a stable amine linkage between collagen and the saccharidic moieties.

The biological activity of neoglycosylated collagen matrices was evaluated with F-11 cells, a neuroblastoma cell line which proliferates in 10\% serum medium but expresses electrophysiological properties of dorsal root ganglion (DRG) neurons under appropriate culture conditions [28]. F-11 was used as the cell line of choice because we previously demonstrated that it is able to generate functional neurons by its maintenance on neoglucosylated collagen matrices [16].

First, cell proliferation was assessed in order to evaluate biocompatibility of neoglycosylated collagen matrices. F-11 cells maintained for seven days on sialyl $\alpha-(2 \rightarrow 6)$-galactoside (4) and sialyl 
$\alpha$-(2 $\rightarrow 3)$-galactoside (5) grafted to collagen matrices showed, respectively, an $85 \pm 14 \%(p<0.001)$ and $25 \pm 5 \%(p<0.05)$ increase in proliferation rate, compared to cells grown on Petri dish. On the contrary, $\beta$-galactoside (3) and chondroitin sulphate (6) collagen matrices did not behave differently from control (Figure 2). Taken together, these data suggest that sialic acids specifically sustain F-11 cell proliferation, while galactosides and chondroitin sulphate do not. It has been shown that gangliosides expressed in neural stem cells and neuroblastomas are different from those present in mature neurons; they are able to interact with the epidermal growth factor (EGF) receptor, allowing proliferation and the maintenance of the undifferentiated state (in neural stem cells) and contributing to the oncogenic properties (in neuroblastomas). In particular, simpler gangliosides featured by a single sialic acid residue are more expressed on neuroblastoma cells and are possibly related to cell proliferation [29]. Since F-11 is a neuroblastoma cell line, this could provide a possible explanation for the proliferative effect of sialic acids we observed. Interestingly, cell proliferation was sensitive to sialoside regiochemistry $((2 \rightarrow 6)$ versus $(2 \rightarrow 3))$.

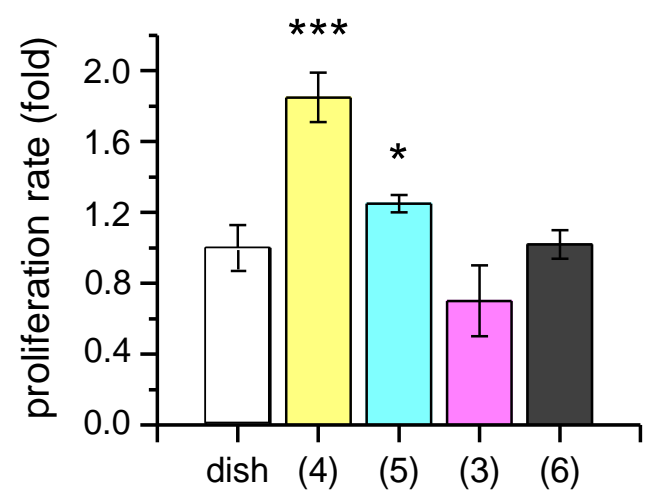

Figure 2. Proliferation rate of F-11 cells seeded and maintained for seven days on different

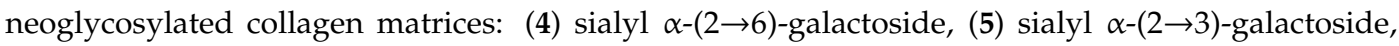
(3) $\beta$-galactoside, (6) chondroitin sulphate. ${ }^{*} p<0.05,{ }^{* * *} p<0.001$.

Since our previous work showed a higher percentage of F-11 cells with neuron-like morphological and functional properties when plated on $\alpha$-glucoside collagen matrices than when plated on pristine collagen or a Petri dish [16], in the new samples we also investigated cell electrical activity. Patch-clamp recordings demonstrated that, conversely to $\alpha$-glucosides, these sugar epitopes did not provide a differentiating pressure on F-11 cells. In fact, the percentage of cells able to generate action potentials (the hallmark of neurons) did not change compared to the Petri dish group, but it was reduced compared to the pristine and $\alpha$-glucoside collagen matrices (2). In particular, the percentages of cells showing electrical activity on sialyl $\alpha-(2 \rightarrow 3)$-galactoside (5), sialyl $\alpha-(2 \rightarrow 6)$-galactoside (4) or chondroitin sulphate (6) collagen matrices were, respectively, 20\%, 14\% and 18\%. Only the $\beta$-galactoside collagen matrix (3) slightly increased this percentage compared to the Petri dish group (63\% of cells on $\beta$-galactoside collagen versus $29 \%$ on Petri dish); however, the difference was not significant $(p>0.05)$ (Figure 3). The inability of $\beta$-galactosides (3) to drive cell behavior is in agreement with previous results [22] showing that biomaterials functionalized with galactosides failed to promote neuronal outgrowth. 


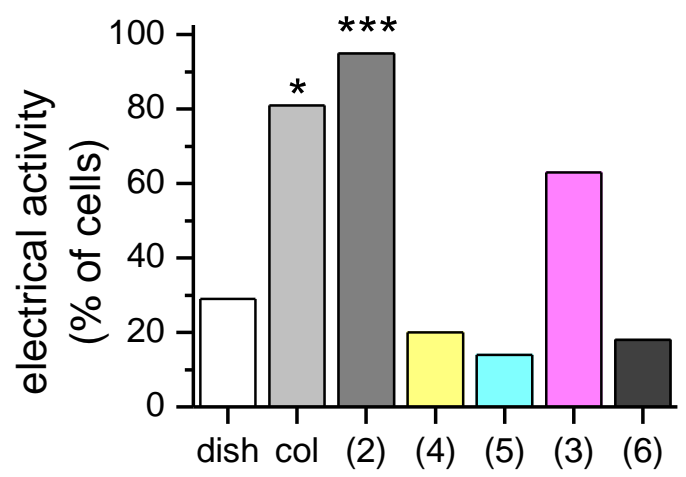

Figure 3. Percentage of F-11 cells endowed with electrical activity on different neoglycosylated collagen matrices: col, pristine collagen; (2) $\alpha$-glucosides, (4) sialyl $\alpha-(2 \rightarrow 6)$-galactoside, (5) sialyl $\alpha$-(2 $\rightarrow 3)$-galactoside, (3) $\beta$-galactoside, (6) chondroitin sulphate. Statistical analysis was performed using the Chi-squared test. Significance was set for $p<0.05$. ${ }^{*} p<0.05,{ }^{* * *} p<0.001$.

\section{Materials and Methods}

\subsection{General Methods}

Solvents and reagents were purchased from Sigma-Aldrich (Saint Louis, MO, USA) and used without further purification. Milli-Q water (mQ) was obtained with $18.2 \mathrm{M} \Omega \mathrm{cm}$ at a $25^{\circ} \mathrm{C}$ purity. Chondroitin sulphate sodium salt (from shark cartilage, CAS number 12678-07-8) and sialyllactosides were purchased from Carbosynth Ltd. (Newbury, UK).

\subsection{Matrices Preparation}

\subsubsection{Pristine Collagen Matrices}

Collagen matrices were prepared from insoluble Collagen Type I from bovine Achilles tendon (Sigma-Aldrich, Saint Louis, MO, USA, catalogue no. C9879) by the solvent casting method [30]. Briefly, collagen powder was suspended in acetic acid $0.5 \mathrm{M}$ at $40{ }^{\circ} \mathrm{C}$ under stirring. After $4 \mathrm{~h}$, the suspension was homogenized with a mixer for $2 \mathrm{~min}$ at maximum speed. After removal of the aggregates, $40 \mathrm{~mL}$ of collagen solution was poured into an $8.5 \times 12.5 \mathrm{~cm}^{2}$ culture multiwell lid, and the solvent evaporated in the fume hood over $48 \mathrm{~h}$. The resulting collagen matrices appeared as transparent films $\left(1 \mathrm{mg} / \mathrm{cm}^{2}\right)$. The film thickness was in the 6-7 $\mu \mathrm{m}$ range, as determined by SEM [18].

\subsubsection{Carbohydrate-Grafted Collagen Matrices}

Carbohydrate-grafted matrices were prepared and characterised as previously described. Grafting chemistry was based on a reductive amination reaction between lysine amino groups of collagen and the carbonyl reducing end of lactose [31], sialyllactosides [18] and chondroitin sulphate [27] in the presence of $\mathrm{NaCNBH}_{3}$ as reducing agent.

$\beta$-Galactose-grafted collagen [31]: collagen matrix ( $80 \mathrm{mg}, 12 \times 7 \mathrm{~cm}$ ) was immersed in $20 \mathrm{~mL}$ of a $0.06 \mathrm{M}$ lactose citrate buffer solution ( $\mathrm{pH}$ 6.00), and a $0.03 \mathrm{M} \mathrm{NaCNBH}_{3} / \mathrm{citrate}$ buffer was added and reacted overnight. The collagen matrix was washed with $20 \mathrm{~mL}$ of Milli-Q (mQ) $(3 \times 20 \mathrm{~min})$, and then finally washed with $20 \mathrm{~mL}$ of ethanol $(20 \mathrm{~min})$.

Sialyl galactosides-grafted collagen [18]: collagen matrices $(80 \mathrm{mg}, 12 \times 7 \mathrm{~cm})$ were immersed in $20 \mathrm{~mL}$ of either a $0.006 \mathrm{M} \mathrm{6}$ '-sialyllactose or a $3^{\prime}$-sialyllactose citrate buffer solution ( $\left.\mathrm{pH} 6.00\right)$, and a $0.003 \mathrm{M} \mathrm{NaCNBH}_{3} /$ citrate buffer was added and reacted overnight. The collagen matrix was washed with $20 \mathrm{~mL}$ of Milli-Q (mQ) $(3 \times 20 \mathrm{~min})$, and then finally washed with $20 \mathrm{~mL}$ of ethanol $(20 \mathrm{~min})$.

Chondroitin sulphate-grafted collagen [27]: a collagen matrix $(1 \mathrm{mg}, 2 \times 1 \mathrm{~cm})$ was immersed in $2 \mathrm{~mL}$ of a $1.5 \mathrm{mM}$ chondroitin sulphate citrate buffer solution ( $\mathrm{pH} 6.00$ ), and a $0.75 \mathrm{mM} \mathrm{NaCNBH} / \mathrm{mitrate}_{3}$ buffer was added and reacted overnight. The collagen matrix was recovered and washed with $2 \mathrm{~mL}$ 
of $\mathrm{HCl} 0.1 \mathrm{M}$ for $10 \mathrm{~min}$, followed by $2 \mathrm{~mL}$ of $\mathrm{NaOH} 0.1 \mathrm{M}$ for $10 \mathrm{~min}, 2 \mathrm{~mL}$ of Milli-Q (mQ) water $(3 \times 20 \mathrm{~min})$ and finally $2 \mathrm{~mL}$ of ethanol for $10 \mathrm{~min}$.

\subsection{Cell Culture}

F-11 cells, a hybrid of N18TG2 mouse neuroblastoma cell line and dorsal root ganglion (DRG) neurons, were seeded at 60,000 cells $/ 35 \mathrm{~mm}$ dish and maintained on the different neoglycosylated collagen matrices for 7 days without splitting. The cells were cultured in Dulbecco's modified Eagle's medium (DMEM, Sigma-Aldrich, Saint Louis, MO, USA), supplemented with $2 \mathrm{mM}$ glutamine (Sigma-Aldrich, Saint Louis, MO, USA) and 10\% fetal bovine serum (FBS, Sigma-Aldrich, Saint Louis, MO, USA) and incubated at $37^{\circ} \mathrm{C}$ in a humidified atmosphere with $5 \% \mathrm{CO}_{2}$. Cells grown on Petri dish and/or on pristine collagen were used as control.

The culture medium was refreshed twice per week. Seven days after seeding, proliferation assay and functional analysis were performed.

\subsubsection{Proliferation Assay and Functional Analysis by Patch-Clamp Recordings}

The proliferation rate was evaluated 7 days after seeding, counting cells by microscopy observations using a Bürker chamber. For each matrix, 3-9 samples were investigated. Electrophysiological analysis was performed by the patch-clamp technique in the whole-cell configuration. Recordings were acquired by the pClamp 8.2 software (Molecular Devices, LLC., San Jose, CA, USA) and the MultiClamp 700A amplifier (Axon Instruments, Molecular Devices, LLC., San Jose, CA, USA) in the current-clamp mode.

Before starting the experiment, the culture medium was replaced with a standard extracellular solution, which was also bath applied during recordings, and contained the following (mM): $\mathrm{NaCl} 135$, $\mathrm{KCl} 2, \mathrm{CaCl}_{2} 2, \mathrm{MgCl}_{2}$ 2, hepes 10, glucose 5 and $\mathrm{pH}$ 7.4. The standard pipette solution contained the following (mM): potassium aspartate 130, $\mathrm{NaCl} 10, \mathrm{MgCl}_{2} 2, \mathrm{CaCl}_{2}$ 1.3, EGTA 10, hepes 10 and pH 7.3.

The parameters we extracted from the recordings were the resting membrane potential $\left(\mathrm{V}_{\text {rest }}\right)$ and the percentage of cells able to generate spontaneous or induced action potentials. The electrical activity was evoked by hyperpolarizing the $\mathrm{V}_{\text {rest }}$ at approximately $-75 \mathrm{mV}$ and subsequently depolarizing the membrane with $600 \mathrm{~ms}$ long current pulses. The depolarization peaks were considered action potentials when they were higher than $0 \mathrm{mV}$. Patch-clamp experiments were performed on 4-9 samples per each matrix, and the recorded cells were $n=21$ for the dish, $n=12$ for native collagen, $n=24$ for (2), $n=10$ for (4), $n=7$ for (5), $n=8$ for (3) and $n=13$ for (6).

\subsubsection{Statistical Analysis}

For the analysis, Origin 8 (Microcal Inc., Northampton, MA, USA) and Excel were used. Data are presented as mean \pm SEM. Statistical evaluations were obtained using one-way analysis of variance (ANOVA), followed by the Tukey post hoc test and the Chi-squared test. Values were considered statistically significant if $p<0.05$.

\section{Conclusions}

Collagen, an interesting biomaterial for regenerative medicine approaches in neuroregeneration, was grafted with different carbohydrates known to be involved in neuronal development and functions. The F-11 neuroblastoma cell line was used as model cells to assess carbohydrate potential in neuroregeneration: $\alpha$-glucosides grafted to collagen were the only carbohydrate epitopes able to drive neuroblastoma cells to differentiate into functional neurons. On the contrary, sialyl galactosides increased cell proliferation, while $\beta$-galactoside and chondroitin sulphate did not show any significant influence on cell behavior.

Author Contributions: Conceptualization, L.C., M.L. and S.V.; Methodology, L.R., A.S. and V.P.; Writing一original draft preparation, L.C., M.L., V.P., A.S. and L.R.; Writing-review and editing, all. All authors have read and agreed to the published version of the manuscript. 
Funding: This research received no external funding.

Conflicts of Interest: The authors declare no conflict of interest.

\section{References}

1. Naqvi, S.; Panghal, A.; Flora, S.J.S. Nanotechnology: A Promising Approach for Delivery of Neuroprotective Drugs. Front. Neurosci. 2020, 14, 494. [CrossRef] [PubMed]

2. Hussain, R.; Zubair, H.; Pursell, S.; Shahab, M. Neurodegenerative Diseases: Regenerative Mechanisms and Novel Therapeutic Approaches. Brain Sci. 2018, 8, 177. [CrossRef] [PubMed]

3. Tam, R.Y.; Fuehrmann, T.; Mitrousis, N.; Shoichet, M.S. Regenerative Therapies for Central Nervous System Diseases: A Biomaterials Approach. Neuropsychopharmacology 2014, 39, 169-188. [CrossRef]

4. Orive, G.; Anitua, E.; Pedraz, J.L.; Emerich, D.F. Biomaterials for promoting brain protection, repair and regeneration. Nat. Rev. Neurosci. 2009, 10, 682-692. [CrossRef] [PubMed]

5. Friess, W. Collagen-Biomaterial for drug delivery. Eur. J. Pharm. Biopharm. 1998, 45, 113-136. [CrossRef]

6. Abou Neel, E.A.; Bozec, L.; Knowles, J.C.; Syed, O.; Mudera, V.; Day, R.; Hyun, J.K. Collagen-Emerging collagen based therapies hit the patient. Adv. Drug Deliv. Rev. 2013, 65, 429-456. [CrossRef]

7. Ucar, B.; Humpel, C. Collagen for brain repair: Therapeutic perspectives. Neural Regen. Res. 2018, 13, 595-598.

8. Kourgiantaki, A.; Tzeranis, D.S.; Karali, K.; Georgelou, K.; Bampoula, E.; Psilodimitrakopoulos, S.; Yannas, I.V.; Stratakis, E.; Sidiropoulou, K.; Charalampopoulos, I.; et al. Neural stem cell delivery via porous collagen scaffolds promotes neuronal differentiation and locomotion recovery in spinal cord injury. NPJ Regen. Med. 2020, 5, 12. [CrossRef]

9. Khaing, Z.Z.; Schmidt, C.E. Advances in natural biomaterials for nerve tissue repair. Neurosci. Lett. 2012, 519, 103-114. [CrossRef]

10. Khaing, Z.Z.; Thomas, R.C.; Geissler, S.A.; Schmidt, C.E. Advanced biomaterials for repairing the nervous system: What can hydrogels do for the brain? Mater. Today 2014, 17, 332-340. [CrossRef]

11. Kucharz, E.J. Collagen in the Nervous System. In The Collagens: Biochemistry and Pathophysiology; Springer: Berlin/Heidelberg, Germany, 1992.

12. Gregorio, I.; Braghetta, P.; Bonaldo, P.; Cescon, M. Disease Models \& Mechanisms Collagen VI in healthy and diseased nervous system. Dis. Models Mech. 2018, 11, dmm032946.

13. Russo, L.; Cipolla, L. Glycomics: New challenges and opportunities in regenerative medicine. Chem. Eur. J. 2016, 22, 13380-13388. [CrossRef] [PubMed]

14. Russo, L.; Sgambato, A.; Guizzardi, R.; Vesentini, S.; Cipolla, L.; Nicotra, F. Glyco-Functionalysed Biomaterials in Neuroregeneration. In Drug and Gene Delivery to the Central Nervous System for Neuroprotection; Sharma, H., Muresanu, D., Sharma, A., Eds.; Springer International Publishing: Berlin/Heidelberg, Germany, 2017; pp. 179-198.

15. Rebelo, A.L.J.; Bizeau, J.; Russo, L.; Pandit, A. Glycan-Functionalized Collagen Hydrogels Modulate the Glycoenvironment of a Neuronal Primary Culture. Biomacromolecules 2020, 21, 2681-2694. [CrossRef]

16. Russo, L.; Sgambato, A.; Lecchi, M.; Pastori, V.; Raspanti, M.; Natalello, A.; Doglia, S.M.; Nicotra, F.; Cipolla, L. Neoglucosylated Collagen Matrices Drive Neuronal Cells to Differentiate. ACS Chem. Neurosci. 2014, 5, 261-265. [CrossRef] [PubMed]

17. Hennet, T. Collagen glycosylation. Curr. Opin. Struct. Biol. 2019, 56, 131-138. [CrossRef]

18. Sgambato, A.; Russo, L.; Montesi, M.; Panseri, S.; Marcacci, M.; Caravà, E.; Raspanti, M.; Cipolla, L. Different Sialoside Epitopes on Collagen Film Surfaces Direct Mesenchymal Stem Cell Fate. ACS Appl. Mater. Interfaces 2016, 8, 14952-14957. [CrossRef]

19. Russo, L.; Battocchio, C.; Secchi, V.; Magnano, E.; Nappini, S.; Taraballi, F.; Gabrielli, L.; Comelli, F.; Papagni, A.; Costa, B.; et al. Thiol-ene mediated neoglycosylation of collagen patches: A preliminary study. Langmuir 2014, 30, 1336-1342. [CrossRef]

20. Russo, L.; Sgambato, A.; Giannoni, P.; Quarto, R.; Vesentini, S.; Gautieri, A.; Cipolla, L. Response of osteoblast-like MG63 on neoglycosylated collagen matrices. MedChemCommun 2014, 5, 1208-1212. [CrossRef]

21. Boggs, J.M. Role of Galactosylceramide and Sulfatide in Oligodendrocytes and CNS Myelin: Formation of a Glycosynapse. In Glycobiology of the Nervous System. Advances in Neurobiology; Yu, R., Schengrund, C.L., Eds.; Springer: New York, NY, USA, 2014; Volume 9. 
22. Kalovidouris, S.A.; Gama, C.I.; Lee, L.W.; Hsieh-Wilson, L.C. A role for fucose $\alpha(1-2)$ galactose carbohydrates in neuronal growth. J. Am. Chem. Soc. 2005, 127, 1340-1341. [CrossRef]

23. Bornhöfft, K.F.; Goldammer, T.; Rebl, A.; Galuska, S.P. Siglecs: A journey through the evolution of sialic acid-binding immunoglobulin-type lectins. Dev. Comp. Immunol. 2018, 86, 219-231. [CrossRef]

24. Snow, D.M.; Brown, E.M.; Letourneau, P.C. Growth cone behavior in the presence of soluble chondroitin sulfate proteoglycan (cspg), compared to behavior on cspg bound to laminin or fibronectin. Int. J. Dev. Neurosci. 1996, 14, 331-349. [CrossRef]

25. Kwon, H.J.; Han, Y. Chondroitin sulfate-based biomaterials for tissue engineering Turk. J. Biol. 2016, 40, 290-299.

26. Tomac, A.; Lindqvist, E.; Lin, L.F.; Ogren, S.O.; Young, D.; Hoffer, B.J.; Olson, L. Protection and repair of the nigrostriatal dopaminergic system by GDNF In Vivo. Nature 1995, 373, 335-339. [CrossRef] [PubMed]

27. Raspanti, M.; Caravà, E.; Sgambato, A.; Natalello, A.; Russo, L.; Cipolla, L. The collaggrecan: Synthesis and visualization of an artificial proteoglycan. Int. J. Biol. Macromol. 2016, 86, 65-70. [CrossRef] [PubMed]

28. Pastori, V.; D’Aloia, A.; Blasa, S.; Lecchi, M. Serum-deprived differentiated neuroblastoma F-11 cells express functional dorsal root ganglion neuron properties. PeerJ 2019, 7, e7951. [CrossRef] [PubMed]

29. Schengrund, C.-L. Gangliosides and neuroblastomas. Int. J. Mol. Sci. 2020, 21, 5313. [CrossRef]

30. Taraballi, F.; Zanini, S.; Lupo, C.; Panseri, S.; Cunha, C.; Riccardi, C.; Marcacci, M.; Campione, M.; Cipolla, L. Amino and carboxyl plasma functionalization of collagen films for tissue engineering applications. J. Colloid Interface Sci. 2013, 394, 590-597. [CrossRef]

31. Russo, L.; Gautieri, A.; Raspanti, M.; Taraballi, F.; Nicotra, F.; Vesentini, S.; Cipolla, L. Carbohydrate-functionalized collagen matrices: Design and characterization of a novel neoglycosylated biomaterial. Carbohydr. Res. 2014, 389, 12-17. [CrossRef]

Sample Availability: Samples of the compounds are available from the authors.

(C) 2020 by the authors. Licensee MDPI, Basel, Switzerland. This article is an open access article distributed under the terms and conditions of the Creative Commons Attribution (CC BY) license (http://creativecommons.org/licenses/by/4.0/). 